\title{
A Systematic Review of Empirically Based Universal Design for Learning: Implementation and Effectiveness of Universal Design in Education for Students with and without Disabilities at the Postsecondary Level
}

\author{
Soonhwa Seok ${ }^{*}$, Boaventura DaCosta ${ }^{2}$, Russ Hodges ${ }^{3}$ \\ ${ }^{1}$ Korea University, Seoul, South Korea \\ ${ }^{2}$ Solers Research Group, Orlando, USA \\ ${ }^{3}$ Texas State University, San Marcos, USA \\ Email: *sunaseok@yahoo.com
}

How to cite this paper: Seok, S., DaCosta, B. and Hodges, R. (2018) A Systematic Review of Empirically Based Universal Design for Learning: Implementation and Effectiveness of Universal Design in Education for Students with and without Disabilities at the Postsecondary Level. Open Journal of Social Sciences, 6, 171-189. https://doi.org/10.4236/jss.2018.65014

Received: March 23, 2018

Accepted: May 21, 2018

Published: May 24, 2018

Copyright $\odot 2018$ by authors and Scientific Research Publishing Inc. This work is licensed under the Creative Commons Attribution International License (CC BY 4.0).

http://creativecommons.org/licenses/by/4.0/

\begin{abstract}
This systematic review explored methods of UDL implementation for postsecondary students with and without disabilities and the degree to which these methods are effective. The authors examined 17 empirically based studies published across 12 journals focused on the application of UDL principles. The studies were analyzed with regard to 1) participant information, 2) courses and delivery mode, 3) independent and dependent variables, 4) implementation strategies, and 5) effectiveness of implementation. The analysis revealed that 15 of the studies reported effective outcomes, one study resulted in blended effects, and one did not discuss implementation. Two studies used a blended delivery mode for special education courses, and four studies used online delivery modes for a teacher education course and three professional development programs. Other studies used face-to-face instruction for teacher education, general courses, and workshops. The most common independent variables were UDL principle-based course design and implementation, followed by hands-on activities, training of instructors, peer-led team learning, and a collaborative professional development model. The dependent variables included course evaluation, learning outcomes, such as revision of lesson plans and technology use, and level of confidence or acquisition of knowledge about UDL and disabilities. Finally, multiple instructional strategies focusing on the UDL principles were utilized, to include web-based computer-mediated communication, web-based class management systems, interactions with technol-
\end{abstract}


ogy and other participants, and learning community. Overall, the findings revealed promising learning outcomes as supported by the existing literature regarding the effectiveness and practicality of UDL for students with and without disabilities at the postsecondary level.

\section{Keywords}

Accessibility, Accommodation, Application of UDL Principles, Design and Implementation of UDL-Based Courses, Modification, Outcomes of UDL Implementation, Postsecondary Education, Students with Disabilities, Systematic Review, Universal Design for Learning

\section{Introduction}

According to the Institute of Education Sciences [1], those with a learning disability (LD) and/or attention deficit hyperactivity disorder (ADHD) collectively represent almost half of all students with disabilities (SDs) attending two- and four-year postsecondary institutions. Their attendance rate $(60.9 \%)$ is lower than those of typically developing students (62.1\%) [2], as is their college completion rate (37.5\% and $51.2 \%$, respectively) [3]. While many reasons have been offered for this discrepancy, these figures reflect the difficulty that SDs experience in adjusting to postsecondary school [4], as they are often not ready for academic college programs [5], showing difficulties in the areas of organization, attention, cognition, and information processing [6].

Students with disabilities at the postsecondary level need programs that adapt to their special needs [7] [8], but at the same time allow the curriculum to be used with all students. To that end, specific strategies have been offered to help students of various educational, cultural, and linguistic backgrounds to succeed in college [9]. However, while considerable research has been conducted on curriculum and/or strategies for increasing learning outcomes for students without disabilities at the postsecondary level (e.g., [10]), few investigations have addressed such solutions for SDs [11].

One of the more promising strategies in this regard is use of the principles of universal design for learning (UDL), which is intended to help all learners succeed [12]. Universal design for learning is based on universal design (UD), originally describing the way buildings and environments can be designed to maximize their inherent accessibility to a diverse body of people [12]. Seven principles serve as the foundation for UD to maximize the accessibility and usability of aggregate surroundings [13]: equitable use, flexibility in use, simple and intuitive use, perceptible information, tolerance for error, low physical effort, and size and space for approach and use.

Regarding UDL, its principles include multiple representations, multiple expressions, and engagement [14]. Multiple representations refer to the provision of choices to modify the visual and auditory information and interface, includ- 
ing the means of communication, letters, or figures. Multiple expressions refer to the provision of multiple ways to express students' knowledge and skill acquisition. Finally, engagement refers to the provision of choices to enhance motivation for learning and options for internal and external factors, such as self-regulation and self-discipline, to maintain motivation. Altogether, these principles offer an outline for instructional actions, such as goals, methods, materials, and assessments, for the purpose of developing built-in, flexible approaches that are available to each student [15]. A number of frameworks for enhancing accessibility and equity for SDs exist, to include UDL, universal design for instruction (UDI), and universal instructional design (UID) [12] [16]. All are similar in approach, with the terms often used interchangeably (e.g., [12] [17]).

Regrettably, empirical examination of UDL implementation and strategies in postsecondary education is lacking, even though numerous studies have been published on the principles, history, and philosophy of UDL [12]. In the context of special education, the reason for this void might be the fact that the Individuals With Disabilities Education Act [18] mandates free appropriate public education (FAPE) for SDs in K-12, but FAPE is not mandated at the postsecondary level [17]. Necessary accommodations (e.g., curriculum and textbooks) for SDs in $\mathrm{K}-12$ are directed and included in their individualized educational programs; however, legal services are not required for SDs at the postsecondary level, and state governments do not offer proactive direction. Compounding matters, while special education teachers in $\mathrm{K}-12$ are specifically trained to teach this population with a focus on pedagogy [17] [19], instructors at the postsecondary level are typically not trained to work with and address the special needs of SDs.

\subsection{Purpose and Research Questions}

This systematic review explored methods of UDL implementation for postsecondary students with and without disabilities and the degree to which these methods are effective. The aim was framed by the following questions:

Question 1: What are the delivery modes of the courses utilized or UDL implementation?

Delivery modes were explored as one of the built-in mechanisms of UDL practices because UDL is believed to enhance accessibility to curriculum. At the same time, delivery mode has not been explored as a built-in mechanism in existing research.

Question 2: What are the independent and dependent variables?

All studies were empirically based. Each study had independent and dependent variables. The outcomes of each study resulted from the implementation of the independent variable as interventions or experiments. The dependent variable was investigated from the intervention. Thus, the independent and dependent variables were explored.

Question 3: What are the strategies used, and are they effective?

Given the fact all studies were empirically based, the UDL implementation 
was used for educational settings. To enhance the efficacy of the independent variables, specific strategies were used in the intervention as the element of UDL. Thus, specific strategies used in the UDL implementation for post-secondary educational settings were explored.

\section{Method}

The authors systematically and independently searched three databases: Educational Resources Information Center (ERIC), PsycINFO, and Professional Developmental Center. The searches were limited to peer-reviewed, empirically based studies published in English. The terms universal design for learning, universal design for instruction, and postsecondary education were used as the descriptors. A total of 102 studies were identified that met these search criteria.

\subsection{Inclusion Criteria}

Each of the 102 studies were independently reviewed for inclusion based on the following criteria: the study had to 1) be empirically based; 2) contain the terms universal design and/or UD, universal design for learning and/or $U D L$, and/or universal design for instruction and/or UDI in the title or abstract; 3 ) have identified the participants; and 4) either implement UDL practices or conduct a survey or interview on UDL intended to enhance knowledge about or implementation of UDL practices for diverse, postsecondary-level learning populations.

Of the 102 studies examined, the authors independently identified 16 studies, among which 14 were common among the authors. This amounted to an $88 \%$ agreement rate on the inclusion criteria use. Some of the 16 studies had been published in the same journals. That is, some of the journals had published two or more of the 16 studies. Upon reviewing these journals, the authors identified two additional studies that met the aforementioned inclusion criteria. The result, therefore, was a total of 18 studies.

The authors together scrutinized the 18 studies in a second review using the same inclusion criteria. This ended in an agreed-upon removal of three studies. Two additional studies were also reviewed because they had been cited by two or more of the remaining studies and met the inclusion criteria. In sum, the removal of the three studies coupled with the addition of the two studies resulted in a final count of 17 studies for review.

\subsection{Data Extraction}

Information was next extracted from the 17 studies in three passes. In the first pass, the studies were summarized for 1) participant information, 2) courses and delivery mode, 3) independent and dependent variables, 4) implementation outcomes, and 5) elements of UDL in the implementation. In the second pass, implementations were further fleshed out, summarizing 6) research methods, 7) implementation strategies, 8) technology implementation, and 9) class activities 
related to the UDL principles. Finally, in the last pass, the effectiveness of the implementations was assessed. That is, the findings were classified as effective, for studies in which the course or instruction for the workshop was designed, implemented, and had higher course evaluation and significant improvement; or blended, if the outcome was not better than or the same as that of the control group, but still showed improvement in the learning assessment.

\subsection{Inter-Coder Agreement}

Inter-coder agreement was assessed on the extracted information using a checklist developed by the authors. The checklist comprised the following six questions: Is the statement about the-1) participant information, 2) courses and delivery mode, 3) independent and dependent variables, 4) implementation outcomes, 5) elements of UDL in the implementation, and 6) assessment of the effectiveness of the implementation-clear and precise?

A total of 102 items (17 studies by 6 checklist items) were assessed. The authors reached an initial agreement rate of $95 \%$ on 97 of the 102 items regarding their belief that the extracted information from the 17 studies was clear and precise, deliberating on the remaining four items until reaching consensus.

\section{Results}

Table 1 depicts the information extracted from the 17 studies, published in 12 journals. That is, 1) participant information, 2) courses and delivery mode, 3) independent and dependent variables, 4) findings, 5) effectiveness of implementation, and 6) elements of UDL in the implementation.

As shown in the table, six studies used mixed methods (see [20]-[25]), seven used quantitative methods (see [26]-[32]), and four used qualitative methods (see [33] [34] [35] [36]). Two studies conducted experimental and control group comparisons (see [26] [31]), while three used pre- and posttests (see [25] [29] [31]). (Table 1 does not call out the implementation strategies in a separate column; rather, the strategies are nested within the other table columns as part of implementation, delivery modes, or elements of UDL.)

\subsection{Participants}

The 17 studies incorporated interviews, surveys, interventions, or control/experimental group experiments. Across the studies, a total of 4879 participants were found, including 3185 (65\%) students at postsecondary institutions, 1605 (32.9\%) faculty members, $16(0.33 \%)$ disability service providers, 35 (0.72\%) administrators, $21(0.43 \%)$ teachers, $5(0.1 \%)$ instructors or teaching assistants, and 12 $(0.25 \%)$ individuals not specified (as teachers or faculty). Of the 3185 students, 57 (1.79\%) were preservice teachers, 136 students (4.3\%) had disabilities, including LD, ADHD, cognitive disability (CD), physical disability (PD), and mobility-related disability (MRD). Six students $(4.4 \%$ of the 136 participants with disabilities) were reported to have a dual diagnosis. No further information 
Table 1. Analysis of Studies.

\begin{tabular}{|c|c|c|c|c|}
\hline Study & $\begin{array}{l}\quad \text { Participants: } \\
\text { - \# of SDs:SwoDs (Students } \\
\text { w/o disabilities) } \\
\text { - Courses } \\
\text { - Delivery Modes }\end{array}$ & $\begin{array}{c}\text { Independent Variables, Dependent } \\
\text { Variables }\end{array}$ & Findings, Effectiveness of the Implementation & Elements \\
\hline [20] & $\begin{array}{l}\text { - } 78 \text { students }(0: 78) \\
\text { - Two special education } \\
\text { classes at two } \\
\text { postsecondary } \\
\text { institutions } \\
\text { - Blended with online } \\
\text { and traditional class } \\
\text { elements }\end{array}$ & $\begin{array}{l}\text { Independent variables. } \\
\text { Design/implementation of instruction } \\
\text { using UDL principles to facilitate } \\
\text { computer-mediated communication } \\
\text { (CMC), in which multiple elements of } \\
\text { online learning and instructional } \\
\text { collaboration were infused between two } \\
\text { teacher preparation courses at two higher } \\
\text { education institutions. } \\
\text { Dependent variables (Data collection: } \\
\text { Mixed method): } \\
\text { - Ways students used CMC tools: Analysis } \\
\text { of chat log (\# of login, frequency of chats, } \\
\text { length of chats, and discussion boards); } \\
\text { theme analysis using data coding patterns. } \\
\text { - Course evaluation: Students' ratings of the } \\
\text { collaborative UDL-based course. }\end{array}$ & $\begin{array}{l}\text { - Significant success in students' class } \\
\text { interaction and participation. } \\
\text { - Elements of UDL principles enhanced } \\
\text { students' participation in discussion. } \\
\text { - Increased variation of types of students' } \\
\text { communication (e.g., chat, discussion board, } \\
\text { asynchronous/synchronous). } \\
\text { - Increased course ratings from the previous } \\
\text { semesters without the implementations. } \\
\text { - Themes of chatting corresponded to existing } \\
\text { literature. Philosophy of teaching, behavior, } \\
\text { technology, and methods of teaching. } \\
\text { - Themes of chatting were emergent from this } \\
\text { research: Socioeconomic status, race and } \\
\text { culture, beliefs or philosophy of individuals with } \\
\text { disabilities, legal requirements, and other. } \\
\text { - Categorized as effective. }\end{array}$ & $\begin{array}{l}\text { - Multiple means of representation: } \\
\text { Implementation of F2F meetings, video, text, and } \\
\text { audio for students at two universities; provision of } \\
\text { discussion and highlighted essential elements; use } \\
\text { of various formats of media. } \\
\text { - Multiple means of expression: Students' choice of } \\
\text { study topic, students' expression of their } \\
\text { knowledge of a topic during online presentations; } \\
\text { various ways of access to the course materials. } \\
\text { - Multiple means of engagement. Groups' choices } \\
\text { of learning goals and schedules for work and } \\
\text { presentations; provision of focused goals allowing } \\
\text { multiple layers of engagement; provision of } \\
\text { asynchronous and/or synchronous discussion } \\
\text { boards. }\end{array}$ \\
\hline [21] & $\begin{array}{l}\text { - } 369: 271 \text { faculty for } \\
\text { survey: } \\
63 \text { faculty and } 35 \\
\text { administrators for } \\
\text { web-based, on-demand } \\
\text { curricular (Faculty and } \\
\text { Administrator Muddles } \\
\text { in Higher Education } \\
\text { (FAME) } \\
\text { - Web-based }\end{array}$ & $\begin{array}{l}\text { Independent variables. Implementation of } \\
\text { web-based FAME: Web-based curricular } \\
\text { FAME made up of five instructional } \\
\text { modules, including accommodation, UDL, } \\
\text { web accessibility, college writing, and } \\
\text { climate assessment; FAME was to enhance } \\
\text { faculty members' understanding of effective } \\
\text { instructional practices. } \\
\text { Dependent variables (Data collection: } \\
\text { Mixed method: Surveys): } \\
\text { - Faculty's preferred training subject and } \\
\text { modes of delivery. } \\
\text { - Perceptions of training SD. } \\
\text { - Teaching methodologies that the faculty } \\
\text { used. } \\
\text { - Professional development needs. } \\
\text { - Evaluation on the effectiveness of } \\
\text { web-based on-demand curricula (called } \\
\text { FAME). }\end{array}$ & $\begin{array}{l}\text { - Preferred subjects listed in order from most to } \\
\text { least preference. UDL, web accessibility, distance } \\
\text { education, adaptive technology, computer lab } \\
\text { accessibility, and accommodations. } \\
\text { - Preferred training modes listed in order from most } \\
\text { to least preference. On demand, web-based, two- or } \\
\text { three-hour workshop, one-hour or daylong } \\
\text { workshop, handouts, training or resources } \\
\text { available anywhere and anytime. } \\
\text { - Instructional method in order from most to } \\
\text { least use: Lecture, class discussion, critical } \\
\text { thinking, or problem solving. } \\
\text { - Faculty's evaluation of FAME: An average of } \\
94 \% \text { of faculty agreement on the appropriateness } \\
\text { of contents and information on professional } \\
\text { development and the needs of SDs. } \\
\text { - } 92 \% \text { agreement on the enhanced comfort as a } \\
\text { result of FAME implementation. } \\
\text { - Categorized as effective. }\end{array}$ & $\begin{array}{l}\text { - Multiple means of representation: Representing } \\
\text { concepts with multimedia; participants' ideas } \\
\text { shared using video clips that were captioned and } \\
\text { included transcripts used for strategic engagement. } \\
\text { - Multiple means of expression: Applied case } \\
\text { scenarios with feedback, pre- and post-assessment } \\
\text { and practice. } \\
\text { - Multiple means of engagement. Videos of } \\
\text { participants' testimonials, including both faculty } \\
\text { and students. }\end{array}$ \\
\hline [22] & $\begin{array}{l}\text { - } 50(2: 48) \\
\text { undergraduates } \\
\text { - Health science } \\
\text { - F2F }\end{array}$ & $\begin{array}{l}\text { Independent variables: Implementation of } \\
\text { the course using UDL principles. } \\
\text { Dependent variables (Data collection: } \\
\text { Mixed method: Course evaluation and } \\
\text { interview): } \\
\text { - Course evaluation: Course materials the } \\
\text { students accessed and the degree of } \\
\text { helpfulness; students' perceived impact of } \\
\text { course components on learning. } \\
\text { - Interviews. Flexibility, social presence, } \\
\text { stress, success. }\end{array}$ & $\begin{array}{l}\text { - Overall benefits from the course for students. } \\
\text { - Reduction in design accommodation for SDs } \\
\text { manually performed by university office of disabilities. } \\
\text { - } 97 \% \text { of participants reported the following to } \\
\text { be helpful: Access to text descriptions of images } \\
\text { in PowerPoint, detailed topic outline, and lists of } \\
\text { key concepts in study guideline. } \\
\text { - Course components that more than } 90 \% \text { of } \\
\text { participants perceived to be very impactful on } \\
\text { their learning. Choice of completing elective } \\
\text { activities or taking a final exam, individual or } \\
\text { group assignment types and paper due dates; } \\
\text { posting instructional materials before class; } \\
\text { consistent format of instructional material } \\
\text { organization on WebCT pages. } \\
\text { - High flexibility of resources. } \\
\text { - Critical factors of social presence: Instructor's } \\
\text { availability outside of class session and his/her } \\
\text { immediacy. } \\
\text { - Shared information using discussion board. } \\
\text { - Stress reduction: Course design and organization, } \\
\text { study guidelines, flexibility of deadlines. } \\
\text { - Students' success. The attributes of UDL design. } \\
\text { - Categorized as effective. }\end{array}$ & $\begin{array}{l}\text { - Multiple means of representation: WebCT, } \\
\text { electronic course material, an online lecture for a } \\
\text { topic, video tutorial, subtitles, PowerPoint slides, } \\
\text { hands-on demonstrations, display of videos, } \\
\text { rubrics, and examples of two formats of } \\
\text { presentations. } \\
\text { - Multiple means of expression: Students' choices } \\
\text { with regard to due dates of assignments, individual } \\
\text { or group assessments, presentation format and } \\
\text { date; multiple-question style on tests; various types } \\
\text { of assignments. } \\
\text { - Multiple means of engagement. Instructor's } \\
\text { welcome email to complete a student profile before } \\
\text { class; multiple types of discussions in class by } \\
\text { email and discussion forums. }\end{array}$ \\
\hline
\end{tabular}




\section{Continued}

[23] - 26 preservice teacher and inservice teachers (16:10)

Online degree certificate program for teachers - F2F instruction for preservice teachers emphasizing assistive technology application

24] - 114 students -F2F special education class with eLearning elements lasting for 1 hour 40 minutes per week - Blended
[25] - 53 faculty: 43: First phase; 10: Second phase - Online disability awareness program during the 2014-2015 academic year
[26] - 413 undergraduate students

- Introductory geology and geography - F2F
Independent variables to UDL: Review and revision of a previously preservice teachers made more revisions using used lesson plan with UDL applications and UDL principles than practicing teachers.

\section{a focus on special learning needs.}

Dependent variables (Data collection: Mixed method)

- Changes in revised lesson plans were quantified and categorized.

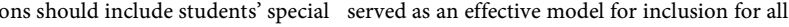
needs in their learning and UDL instructional students. strategies using the three UDL principles. - Categorized as effective.

- Participants' reflections on their assignment were coded using a code book.
Independent variables. Implementing a

web-enabled F2F class focusing on online team collaboration (online teams of nine each) to complete eight assignments durin the semester; a different case of a student with special academic needs (e.g., $\mathrm{LD}, \mathrm{ADHD}$, and gifted) was assigned to each team. The design of the course using adult learning tenets and UDI principles. Course management system (CMS) used to combine eLearning elements with those of traditional class sessions. Dependent variables (Data collection: Mixed method):

- Observation and analysis of participation. - Online interactions. Discussion, products, and feedback.

- Course evaluations.

Independent variables

The online disability awareness program made up of three modules. Two or three hours to complete each module. Module 1 on disability laws, related services and accommodations, and disability. Module 2 on UDL principles and models of UDL strategies and instructiona activities. Module 3 on ways to develop easy-to-approach teaching materials (e.g., syllabi, presentations, and documents). Dependent variables (Data collection: Mixed method)

Quantitative measures

- Faculty attitudes toward SDs using Interaction With Disabled Persons Scale. - Pre- and post-surveys on faculty knowledge about disability laws, disability characteristics, accommodation policies, UDI, and accessibility of electronic materials, as discussed in the online disability awareness program. - Qualitative analysis.

Thematic analysis method.

Independent variables Captioned conditioning (Close-captioned TED Talk on climate change). Dependent variables (Data collection: $A$ composite score from two-captioning or no-captioning - conditioned groups): Test booklets used to test remembrance of information: Short-answer, 12 fill-in-the-blank questions, and multiple choice.
- Increased interaction: The blended course design enhanced students' engagement in meaningful learning.

- Enhanced learning autonomy and self-directed discussion thread).

learning: Choices of what to study, how to engage, and when to engage.

Increased critical reflection skills through the - Minimizing physical efforts. Online and learning community activities and skills of positive collaboration.

The score of course evaluation was 9.2 out of 10 - Perceptible information: The design of CMS to points (10 indicating outstanding).

Categorized as effective.

easily access the instructional materials (e.g., all germane information located in a place)

- Community of learners: Course made use of team interactions and communications between students and between students and professors. - Simple and intuitive. Design of the blended course resulted in effective interactions.

- Improvement of faculty attitudes toward SDs. - Text-, audio-, and video-based materials of the A statistically significant difference between before online program that allow faculty to access the and after completion of program (Pretest: $M=$ program anywhere and anytime. 3.06, $S D=0.54$; Posttest. $M=2.82, S D=0.47)$; $t(42)=3.90, p<0.01, d=0.47$; less discomfort in $\quad-$ Multiple means of representation: Hands-on interactions with SDs; better understanding of activities, discussion, computer-aided instruction, SDs' academic needs and thoughts/ideas. - Increase in knowledge about SDs and principles of Blackboard). $U D L$ : Significant increase from the pretest $(M=-$ Multiple means of expression: Productivity 22.51, $S D=7.48)$ to the posttest $(M=36.09$, SD software, online delivery system, (e.g., $=2.42) ; t(43)=-12.19, p<0.01, d=2.44$. Blackboard).

- Acquisition of new terms and concepts. - Multiple means of engagement. Discussion, - Faculty's confidence and willingness to implement UDI principles in their instruction: More than $86 \%$ of participants rating themselves as confident about disability laws, legal definition of disability, UDI, faculty responsibilities, making adequate accommodations, creating accessible documents, types of campus services available, and finding additional support.

- Categorized as effective.

- Support of close captioning to recall information. - Statistical significance between two groups $(t(411)=5.105 ; p=0.000 ; d=0.51 ;$ Captioning group. $M=18.49 ; S D=3.37, n=194$; No-captioning group: $M=16.67 ; S D=3.81, n=219)$.

- Exposure to video instruction and captioning. $7 \%(n=29)$ with no exposure to a course-related video; $60 \%(n=247)$ with occasional exposure to close captioning while course-related videos were incorporated; $30 \%$ ( $n$ while course-related videos were incorporated. $=126$ ) with no exposure to close captioning - Categorized as effective.
- Multiple means of representation: Close-captioning video. productivity software, utilizing electronic media online delivery system, (e.g., Blackboard).

- Beside the implementation, to implement the effective workshop, Technology Needs Survey was conducted prior to the workshop to plan it.
- Equitable use: Enhanced and easy access by all students with multiple learning abilities (e.g., 


\section{Continued}

[27] - 928 undergraduate Independent variables: Implementation of - The perceived effectiveness of each tool with - Multiple means of representation: Lecture in students a UDL environment.

- A large Dependent variables (Data collection: undergraduate Quantitative method: Survey):

marketing management - Effectiveness of UDL environment on course during spring the last day of class.

and fall - Students' satisfaction.

$-\mathrm{F} 2 \mathrm{~F}$

- Perceived effectiveness, use of various instructional tools, and perceived learning.

- Actual learning: An average of student non-cumulative scores from three exams over the course. significant difference $(p<0.001)$ as shown in class, PowerPoint presentations, printed and the order from most to least: Perceived lecture electronic textbooks, MindTap ReadSpeaker notes (audio).

- $(M=4.5, S D=0.89)$, PowerPoint $(M=4.4, \quad$ - Multiple means of expression: Lecture notes, $S D=0.84)$, clickers $(M=4.2, S D=0.99)$, and clickers, MindTap flashcard, MindTap dictioMindTap $(M=3.9, S D=1.22)$, indicating nary, MindTap notebook.

students' preference for professors' developed - Multiple means of engagement. Before-lecture content over that of others; instructional tools available both in and outside the classroom (e.g., PowerPoint, MindTap, and lecture notes) assignments, fill-in-the-blank exercises, quizzes, perceived to be more effective than tools only accessible from class (e.g., clickers).

- Actual use of MindTap added 0.36 points to - Actual use of tools: Total number of uses test scores $(\beta=0.36, p<0.001)$, meanwhile the of each instructional tool (clicker and MindTap) analyzed by online analytics. use of clickers was not significant $(\beta=-0.004$, $p=0.95)$.

- Perceived (self-reported) use and actual use of tools indicated a strong and positive correlation: Clickers $(r=0.22, p<0.001)$ and MindTap $(r=0.10, p=0.002)$.

- Categorized as effective.

[28] - 1195 faculty: $231 \quad$ Independent variables: from a university in the U.S.; 315 from a university in Canada; 649 from 43 universities in Spain - F2F teaching and assessment.
In the U.S.: Intense 4-day workshop, e-newsletters, website resources; Topics the workshop: Disability, legal means, accommodations, and alternative and inclusive strategies for instruction

In Canada: Workshop on faculty attitudes toward SDs and instructional practices.

In Spain: Unknown.

Dependent variables (Data collection: Quantitative method):

The Inclusive Teaching Strategies Inventory used.

- Faculty attitudes.

- Actions.

- Measurement dimensions:

Accommodations, accessible course materials, course modification, inclusive lecture strategies, inclusive classroom, inclusive assessment, and disability laws and concepts.

[29] - 1367 students and instructors; 5 instructors; 1362 (106 [8\%]: 1256): pre-survey (during the 3 rd week of the semester);

1,223 (98 [8\%]: 1125): post-survey (during the last two weeks of the semester)

- Large "gateway" introduction to psychology

- F2F

\section{- Independent variables}

UDL training for the five instructors once a week for a semester. F2F training and

provision of electronic tutorials of

universally designed electronic materials. Dependent variables (Data collection: Quantitative method: Survey):

- Effectiveness of UDL training as measured by students' perceptions of instructors' UDL implementation.

- Pre- and post-surveys contained the same questions.

- Attitude: The components that U.S. faculty believed significant were the provision of $f$ accessible course materials, inclusive classroom, inclusive lecture strategies, inclusive assessment, and course mediation; the components that Canadian faculty believed significant were the provision of accommodations and knowing laws and concepts of disability.

- Actions. Implementations by U.S. faculty. Inclusive assessment and course modifications in their teaching practices; Those by Canadian faculty. Integrated accommodations into their class; Those by Spanish faculty. Provision of accessible course materials and inclusive lecture strategies.

- The ratings of dimension of inclusive classrooms were similar across the three countries.

Categorized as effective.

- The instructors reported significant improvement in UDL strategy implementation.

- Areas with significant enhancement. Information presentation in multiple formats $(t(2559)=10.09, p<0.0005, d=0.40)$, provision of the electronic equivalents of traditional copies of information $(t(2504)=$ $6.13, p<0.0005, d=0.24)$, online availability of required readings $(t(2393)=8.74, p<$ $0.0005, d=0.36)$, clarity of instructional video $(t(2520)=9.62, p<0.0005, d=0.39)$, provision of prompt, constructive, and informative feedback $(t(2515)=8.14, p<$ $0.005, d=0.33$ ), and provision of visual supports for lecture and reading assignment $(t(2556)=5.14, p<0.0005, d=0.20)$.

- Categorized as effective.
- Multiple means of representation: Instructors presented information using lecture, text, graphics, audio, and video.

- Multiple means of expression: Students expressed their knowledge using traditional tests, written essays, projects, and portfolios.

- Multiple means of engagement. Investigation of students' motivation and challenges and instructors' enthusiasm for the subject matter. 


\section{Continued}

[30] - 80 graduate students enrolled in an introductory research method course for fou semesters (spring 2010:18, fall 2010:14 spring 2011:33, fall 2011:15)

- Introduction to research method - F2F
Independent variables. Research method course was taught using is listed in the column of Elements of UDL UDL strategies with the modification of the Curriculum.

traditional research method course (emphasizing instructor's action based on students' feedback).

Dependent variables (Data collection: Quantitative method: Students paper-based survey): Student evaluation of learning and instruction at the end of the semester Strategies used, instructional consistency with the principles of UDL, and students' perceptions of the degree and ways of student engagement were surveyed. .43), reading lecture notes $(M=2.37, S D=$ $(M=2.33, S D=0.84)$

- The strategies students used least for UDL recognition learning network Listening to text-
- The strategies students most frequently used for UDL recognition learning network: Reading summarizing handouts $(M=2.87, S D=0.43)$, listening to an in-class lecture $(M=2.84, S D=$ to-speech software $(M=0.05, S D=0.22)$, accessing online digital course materials (e.g., Blackboard, $M=0.61, S D=1.04)$, and listening to recordings of course topics $(M=0.65, S D=0.87)$. - The strategies students most frequently used for UDL strategic learning network. Hands-on activities $(M=2.81, S D=0.42)$, word processo or other $(M=2.76, S D=0.68)$, and spell checker to check written work $(M=2.67, S D=0.70)$. The strategies students least used for UDL strategic learning network: Speech-to-text $(M=0.04, S D$ $=0.191$, inclusion of hyperlinks in assignments $(M=1.1, S D=1.13)$, and inclusion of images or video in assignment $(M=1.3, S D=1.1)$. - The strategies students preferred: Feedback from the instructor $(M=2.65, S D=0.51)$, choice of assignment topics $(M=2.35, S D=$ 0.73 ), and choice of assignment materials ( $M=$ 2.28, $S D=0.73$ ).

- Categorized as effective.

[31] - 72 graduate and Intervention: One-hour in-class lecture to undergraduate students the experimental group on how to change - Two special education lesson plans for students with mild and and two general education classes - F2F

- Information needed about UDL approaches severe disabilities incorporating the ULD principles (experimental group design) Dependent variables (Data collection:

Quantitative method)

- Professor-developed scoring rubric with zero-to-two points used.

- Pre/posttest scores on students' modified lesson plans. for the teachers to design lesson plans for diverse learners.

- The effectiveness of UDL both for the special and general education teachers. Statistically significant scores on pre and posttests $(F(1,68)$ $=52.027, p<0.001, \eta^{2}=0.433$; representation component, $F(1,68)=31.416, p<0.001, \eta^{2}=$ 0.316 ; expression component, $F(1,68)=46.069$, $p<0.001, \eta^{2}=0.404$; and engagement component, $\left.F(1,68)=6.830, p=0.011, \eta^{2}=0.091\right)$. - Significant improvement indicated by results of pre- and posttests of the experimental group between pre- $(M=0.98)$ and posttest $(M=3.34)$ compared to those of control group's pre- $(M=$ $0.77)$ and posttest $(M=0.077)$

- Categorized as effective.

- Persistence in STEM course

- Growth in using learning strategies measured by LASSI pre- and post-group tests: Significan improvement shown with $0.05 \%$ level in the group means of skill cluster (pretest; posttest

- Persistence: Enrollment in a STEM clas for the next semester.

- Scores from Learning and Study Strategies For three clusters, single-tailed test was Inventory (LASSI)
Multiple means of representation (recognition learning): Provision of online learning management system, posted class notes, PowerPoint slides, links to files in different formats, and reading materials. Multiple means of expression (strategic learning): Provision of timely feedback, hands-on sentence-completion activities, trading cards in front of which the researcher's picture was displayed with facts about him/her on the back, students' role-playing favorite researcher by sharing research with classmates, and poster session at the end of the semester.

- Multiple means of engagement (affective learning): Administration of multiple-intelligences inventory to learn about students, small-group discussion, provision of choice of topics in assignments, students developing blogs to post their thoughts on class topics, and resources from YouTube.

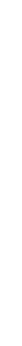

Multiple means of expression: One-hour class lecture comprised of presentations on the UDL principles and implementations; elements unknown. and ADHD

- STEM courses; for two semesters F2F $42^{\text {nd }} ; 66^{\text {th }}$ percentile with a probability value of 0.005 ), will cluster (pretest; posttest $=42^{\text {nd }} ; 63^{\text {rd }}$ percentile with a probability value of 0.005 ) and self-regulation cluster (pretest; posttest $29^{\text {th }} ; 56^{\text {th }}$ percentile with a probability 0.001 ).

Dependent variables (Data collection: Quantitative method): applied.

- Lower academic performance of PLTL SDs than non-PLTL SDs in the STEM courses. PLTL SDs might be the most at-risk subgroup on campus.

- Categorized as blended.
In peer mentors' training. Instructions on UDI principles and matching them with learning characteristics of students with LD and/or ADHD. Multiple means of representation (from peer mentors): Written templates, such as paper-based charts, lists, or diagrams, video templates, and color codes from red to blue on the whiteboard. Multiple means of engagement (in PLTL): Building the learning community with peers and mentors. 


\section{Continued}

[33] - 15 students (12:3): 11 Independent variables undergraduate; 5 with LD/CD; 5 with PD; 6 with more than one disability (4 with MRD, Dependent variables (Data collection: 1 with PD, and 1 with LD)
Common phenomenon between SDs and SwoDs called a phenomenological approach.

Structured interview using an interview protocol):

- SDs' perceptions of instructional methodologies and strategies to enhance their learning.

- Matching SDs' perception of UDL principles.
[34] - 16 disability service providers at postsecondary institutions; two focus groups of eight $-\mathrm{F} 2 \mathrm{~F}$
Independent variables.

- Keynote presentation addressing UDI principles, construct, and application for instruction for student with LD (SLD), and inclusion using UDI.

- Focus group discussion.

Dependent variables (Data collection: Qualitative method)

- Responses to open-ended questionnaires of the protocol developed by UDI project team with foci on experiences with or teaching SLD/ADHD and analysis of discussion.

- Perceptions of the strengths and weaknesses of UDI as a strategy for faculty to increase inclusion in their teaching.

- Perceptions of the participants' responsibility for enhancing UDI on campus.

- Perceptions on office for students with disabilities (OSD) supports to incorporate UDI as strategies of faculty development. - Focus group discussion audiotaped, transcribed, and analyzed as data: Code book and multiple processes of interrater reliability were used.
- Perceptions of instructional methodologies and strategies found to enhance learning. SDs materials. addressed issue more than SwoDs; organization - Flexibility of use: Class discussion or small-group of physical environment (11 SDs vs. 2 SwoDs), discussion. equity ( 9 SDs vs. 1 SwoD), the degree of - Simple and intuitive: Clarity of class professors' familiarity with disabilities (11 SDs), expectations. frustration with accommodations and policies (9 - Perceptible information: Dissemination of class SDs), stigma associated with disabilities (7 SDs), outlines ahead of time.

and stress from dependency on others, need for - Tolerance for error. Frequent feedback before extra time for study, and challenges with final grades of the projects.

transportation. - Low physical effort. Use of screen reader. - Accommodation issues. Satisfaction from nine - Size and space for approach and use. Transitions SDs; Students' concerns. Inadequate time given between classes.

for tests; faculty members' lack of understanding - Community of learners. Tutors, counseling SDs; lack of provision of built-in services, and class and small-group discussion. accommodations (e.g., human reader vs. built-in - Multiple means of representation: Equitable use, computer screen reader); functional mismatch flexibility of use, perceptible information, between SDs' needs and technology (e.g., voice tolerance for error. recognition software for the students with communication impairment [CI]).

- Learning preference: Varied between learners, but the flexible combination of learning preferences leading to the best learning outcomes.

- The highest learning preferences by SDs, visually $(n=3)$, hands-on $(n=3)$, picture graphs, charts $(n=3)$, and practice or demonstration $(n=3)$. The least preferred methods were explanation with words $(n=2)$. - Matching SDs perception of UDL principles. Effective strategies based on the SDs perception: Class and small-group discussion, clarity of class expectations, dissemination of class outlines and instructional materials before class, frequent feedback before the final grades of the projects, writing center, general feedback, screen readers, use of computer, transition from class to class, tutoring, and counseling services.

- Benefits of UDI implementation: Increased instances of enrollment and graduation of students with different cultural backgrounds, adequate instructional approaches to all students, support for data-based teaching practices, and decrease in stigma related to disabilities.

- Weakness of UDI implementation: Faculty resistance, training issues, technology requirements, lack of students' self-advocacy, lack of instructional knowledge of service providers, and legal void of UDI implementation.

- Perceptions of participants' responsibility. Widely spreading knowledge about UDI to campus leadership, collecting data and supporting faculty who incorporate UDI in their teaching, and facilitating faculty members' UDI implementation, different appreciation from a campus based on culture and disciplines.

- Perceptions of OSD supports. Supports needed from campus leaders to incorporate UDI; provision of knowledge about UDI, including information about instructional technology and research on the efficacy of UDI.

- Findings from the interviews. Data collection as a facilitator of UDI implementation; service providers' expertise - learning strategies vs. faculty members' expertise - the content areas. - Categorized as effective.
- Multiple means of expression: Flexibility of use, perceptible information, tolerance for error, low physical effort, instructional climate. - Multiple means of engagement. Flexibility of use, simple intuitive (clarification of class expectations), tolerance for error, low physical effort, size and space of approach and use, a community of learners, and instructional climate. 


\section{Continued}

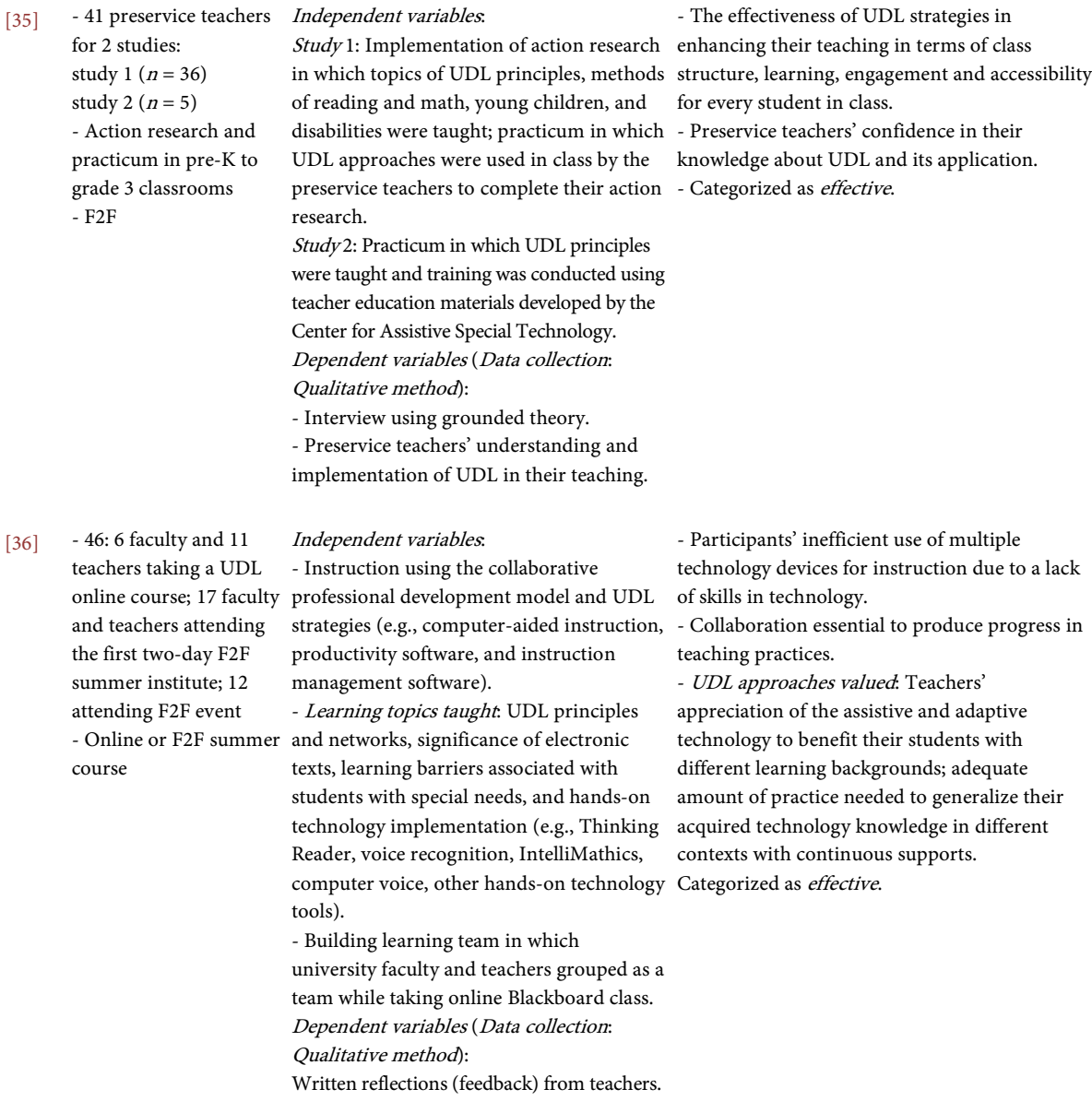

was offered regarding the number of participants in each of these disability categories.

\subsection{Courses and Delivery Mode}

Ten studies were conducted in the students' classrooms (see [20] [22] [23] [24] [26] [27] [29] [31] [32] [35]). One study was conducted outside of the classroom as peer-mentoring team teaching, but the outcomes were measured using grade-point average (GPA) taken from science, technology, engineering, and math (STEM) courses for which tutoring was provided (see [32]). Two studies used a blended approach (see [20] [24]). Three studies were conducted in special education courses: two used a blended delivery (see [20] [24]), and one was delivered as face-to-face (F2F) (see [31]). Twelve studies used F2F for courses other than special education (see [22] [23] [26]-[32] [34] [35] [36]). Although the lev$\mathrm{el}(\mathrm{s})$ of special courses was/were not specified, the courses targeted the undergraduate and graduate level. The undergraduate courses comprised the topics of geology, geography, marketing management, health science, calculus, and chemistry; the graduate course taught research methods for 80 students.

Professional development programs were described in studies as having been 
designed and utilized for faculty (see [21] [25] [28]), disability providers (see [34]), administrators (see [21]), and teachers (see [36]). Two programs were described as F2F (see [28] [34]) while three were web-based (see [21] [25] [36]). In Zhang's [36] study, for example, faculty and teachers were teamed to implement a collaborative UDL solution. Topics included UDL approaches, accessibility, accommodation, and disability laws and regulations. Overall, 16 of the 17 studies described UDL-based implementations.

\subsection{Independent and Dependent Variables}

\section{Independent Variables}

Regarding UDL implementation, a variety of independent variables were identified. Eleven studies described investigations focused on increasing learning outcomes. The most frequently used independent variables were UDL-based course design and implementation (see [20] [22] [24] [27]). Multiple variables were used only once, which included captioned conditioning (see [26]), assignment activities related to revision of lesson plans (see [23]), action research and practicum (see [35]), UDL training for instructors (see [29]), traditional course revision (see [30]), lecture on the lesson plan revision (see [31]), and peer-led team learning (PLTL) implementation (see [32]).

Implementation for faculty members took the form of professional development programs, with each study using a different type of program. The independent variables included keynote presentation on UDL and focus group discussion (see [34]); implementation of five instructional modules, including accommodation, UDL, web accessibility, college writing, and climate assessment (see [21]); intensive workshops (see [28]); an online disability awareness program (see [25]); and instruction using the collaborative professional development model and UDL strategies (see [36]).

\section{Dependent Variables}

Multiple dependent variables were also measured. Six studies evaluated UDL-implemented courses using course evaluations (see [20] [22] [24] [27] [29] [30]), which included measures of effectiveness, flexibility, learning outcomes, course accessibility, and accommodations. Other measures focused on the degree of the instructor's social presence (see [22]). These included interactions with the instructor in and outside the class with immediacy; the number of class interactions using technology and discussion (see [20] [24] [27]); the relationship between use of technology and grades or learning (e.g., the relationships between the frequency of using tools and academic scores, see [27]) and products. The products were made by the students as the effect of the UDL implementations. These products included the revision of lesson plans (see [23]), development of the modified lesson plans (see [31]), GPA (see [32]), and preservice teachers' UDL implementation in their own classes (see [35]). Studies also collected and analyzed preservice teachers' reflections on their perceived level of knowledge acquisition on UDL implementation from the courses as a transfor- 
mative pedagogy for diverse students (see [23] [35]).

Furthermore, perceptions of UDL implementation, participants' discussions, confidence in UDL implementation, attitudes and actions toward SDs, effectiveness of the programs, knowledge about UDL, accommodations and disability-related issues, and level of knowledge acquisition were commonly measured across the studies using professional development programs (see [21] [25] [28] [34] [36]). Finally, preferred training subjects and program delivery modes were also explored (see [21]).

\subsection{Implementation Strategies}

Regarding strategies, nine studies delineated or listed UDL approaches matching UD or UDL principles (see [20] [21] [22] [24] [27] [29] [30] [32] [33]). Three principles were sustained in each study using various strategies. These strategies included web-based computer-mediated communication, provision of text, audio, and video learning materials, discussion, web-based class management systems, interaction with technologies, team collaboration strategies, and learning community (see [20] [22] [24] [32]). Traditional instruction was also used (see [23] [35]). Furthermore, group or individual assignments and hands-on activities were employed to enhance the principles of multiple expression and engagement (see [22] [23] [35]). Course modifications in some studies were made based on student feedback (see [29] [30]), while for professional development programs, "anywhere and anytime" web-based instruction, web-based workshops, and web-based information were generally utilized (see [21] [25] [28]).

\subsection{Effectiveness of Implementation}

Implementation of the interventions was generally reported to be effective. The outcomes of captioned conditioning (see [26]) and revision of the lesson plans (see [31]) were reported effective with statistically significant differences for effect sizes from the control/experimental group comparison. The outcomes from the studies using pre- and posttests (see [25] [29] [31]) were also reported effective with statistical significance. Improvement was reported in the following areas: application of learning strategies of students with LD and ADHD across two semesters (see [32]); participation in discussion, interaction with technology, and reflection skills (see [20] [22] [24]); and confidence in technology skills (see [23] [25] [35] [36]).

\section{Discussion}

This systematic review revealed that the outcomes of UDL implementation in 15 of the 17 studies examined were effective for coursework or professional development programs. This finding is promising, suggesting the value of applying UDL principles [37] [38].

Specifically, the studies reflected different aspects of UDL implementation, including interaction, knowledge acquisition, technology use, modification and 
accommodation for SDs, and related laws and regulations [39] [40]. The studies also offered different perspectives and learning outcomes for both professionals and students at the postsecondary level (faculty, teachers, service providers, or administrative staff and students). In this context, effectiveness of UDL implementations was found among both groups. The studies that used group comparison between experimental and control groups found statistically significant differences between them, consistent with the larger body of research [39] [41]. Furthermore, the studies using pre- and posttests found significant improvements between training with and without implementation, likewise aligned with the group comparison studies (see [25] [29] [31]). Finally, the results from the comparison studies addressing the importance of teacher education were consistent with those of existing studies [39] and across the studies included in this review (see [20] [23] [24] [31] [35]), further indicating the overall value of UDL at the postsecondary level.

Of particular importance was the finding that participants with LD and/or ADHD did not perform better in their STEM courses than their peers with other disabilities who did not participate in PLTL. As a result, further research should address these findings with a particular focus on examining different disabilities, at-risk groups on campus, and other identified variables [42].

Also, of importance, three studies discussed students' use of products to evaluate the effectiveness of the UDL implementation. The results suggested that the best approach was comprised of professors' instruction with examples, students' practice and products using hands-on activities, and feedback and assessments (see [23] [27] [31]). These findings are aligned with the other studies in this review, showing student preference for in-house teacher-made instructional materials over commercial materials [27] and the effectiveness of hands-on activities [23] [31] [33]. Overall, processes of instruction were aligned with one of the evidence-based practices in other disciplines [43] [44]. That is, behavior skills training comprised of instruction, rehearsal, and feedback. Behavior skills training is generally used for teachers and students in the training of individuals with developmental disabilities.

It is also important to emphasize that less than $5 \%$ of the participants sampled in the 17 studies were reported to have disabilities. This might explain the discrepancy in the number of enrollments and class attendance rates for these students (see [21] [29]), which was aligned with existing reports [2] [3] [45]. Although SDs were not representative, by and large, information from the participants suggests that UDL application was effective for all students sampled, whether they had disabilities or not. These are findings consistent with existing research [46].

The review also revealed that teacher education courses were described in some of the studies as involving students with and without special needs (see [20] [24] [31]), in practicum (see [35]), and in teacher education courses (see [23] [36]), thus, offering examples of special education teachers' training for SDs 
in K-12 settings. Extrapolated, these findings may suggest that information about UDL and related strategies should be taught to pre- and inservice teachers to improve instruction and learning outcomes as part of their teaching practices-a conclusion that is supported by and aligned with findings reported in the literature [47] [48].

Another finding is the importance of considering students' needs when providing instruction and accommodations. In Smith [30], students listened to in-class lectures more than using other accommodations to learn and study. At the same time, they least utilized a speech-to-text device to learn and study. This finding is aligned with other investigations, such as that of Black et al. [33], in which SDs reported inappropriate accommodations and mismatches between their needs and accommodations or modifications provided. While this may be viewed as a finding emerging from this investigation at the postsecondary level, such a discovery has been addressed in secondary education [49], revealing an important implication for the provision of accommodations and modifications.

The instructional strategies were found to match UD or UDL principles across the included studies. The strategies were nested in eLearning (e.g., web-based asynchronous vs. synchronous discussion; distance learning for two different classrooms at two different institutions; anytime-, any place-based), adult learning (e.g., learning autonomy, self-discipline), and traditional learning (e.g., in-class lecture). One of the strengths of web-based instruction is its flexibility in terms of time and space to promote learning as well as its inherent ability to handle built-in accommodations and modifications [50] [51]. Most of the courses described in the 17 studies utilized web-based management systems, although some also included F2F instruction. It is, therefore, reasonable to conclude that web-based instruction or eLearning could be applied as an effective delivery mode of UDL implementation to enhance built-in accessibility. This may be viewed as a new finding resulting from this investigation. As stated, delivery modes were viewed in this review as one of the built-in mechanisms of UDL practice but have been mostly excluded as such in the existing research.

Finally, the most frequent independent variables were design and implementation of UDL-based courses. Other independent variables included strategies to facilitate UDL implementation, such as revisions and modifications of lesson plans; training instructors to enhance learning outcomes and interaction; use of technology; and learning community. All in all, the findings reinforce the value of UDL-based blended instruction, focusing on the three UDL principles of multiple means of representation, expression, and engagement.

\section{Conclusion}

This systematic review examined 17 empirically based studies focused on UDL implementation, presenting a discussion on the value of UDL supported by existing research. Altogether, the analysis revealed that these studies, conducted on 
the application of UDL principles, showed that this approach was effective; thus, underscoring the benefits of UDL in educating students with and without disabilities at the postsecondary level.

\section{References}

[1] Raue, K. and Lewis, L. (2011) Students with Disabilities at Degree-Granting Postsecondary Institutions. U.S. Department of Education, National Center for Education Statistics, Institute of Education Sciences, Washington DC. https://nces.ed.gov/pubs2011/2011018.pdf

[2] Cameto, R., Knokey, A.-M. and Sanford, C. (2011) Participation in Postsecondary Education of Young Adults with Learning Disabilities: Findings from NLTS2. Learning Disabilities: A Multidisciplinary Journal, 17, 45-54.

[3] Farmer, J.L., Allsopp, D.H. and Ferron, J.M. (2015) Impact of the Personal Strengths Program on Self-Determination Levels of College Students with LD and/or ADHD. Learning Disability Quarterly, 38, 145-159. https://doi.org/10.1177/0731948714526998

[4] Morningstar, M.E., Frey, B.B., Noonan, P.M., Ng, J., Clavenna-Deane, B., Graves, P., Kellems, R. and Williams-Diehm, K. (2010) A Preliminary Investigation of the Relationship of Transition Preparation and Self-Determination for Students with Disabilities in Postsecondary Educational Settings. Career Development for Exceptional Individuals, 33. 80-94. https://doi.org/10.1177/0885728809356568

[5] Thurston, L.P., Shuman, C., Middendorf, J.B. and Johnson, C. (2017) Postsecondary STEM Education for Students with Disabilities: Lessons Learned from a Decade of NSF Funding. Journal of Postsecondary Education and Disability, 30, 49-60.

[6] Seok, S., DaCosta, B., Kinsell, C., Poggio, J.C. and Meyen, E.L. (2010) Computer-Mediated Intersensory Learning Model for Students with Learning Disabilities. TechTrends, 54, 63-71. https://doi.org/10.1007/s11528-010-0385-4

[7] DaCosta, B. and Seok, S. (2010a) Human Cognition in the Design of Assistive Technology for Those with Learning Disabilities. In: Seok, S., Meyen, E. and DaCosta, B., Eds., Handbook of Research on Human Cognition and Assistive Technology: Design, Accessibility and Transdisciplinary Perspectives, IGI Global. Hershey, 1-20. https://doi.org/10.4018/978-1-61520-817-3.ch001

[8] DaCosta, B. and Seok, S. (2010b) Managing Cognitive Load in the Design of Assistive Technology for Those with Learning Disabilities. In: Seok, S., Meyen, E. and DaCosta, B., Eds., Handbook of Research on Human Cognition and Assistive Technology. Design, Accessibility and Transdisciplinary Perspectives, IGI Global. Hershey, 21-42. https://doi.org/10.4018/978-1-61520-817-3.ch002

[9] Hodges, R., Seller, D. and Dochen, C.W. (2001) Implementing a Learning Framework Course. In: Hodges, R., Simpson, M.L. and Stahl, N.A., Eds., Teaching Study Strategies in Developmental Education: Readings on Theory, Research, and Best Practice, Bedford St. Martin's, Boston, 314-325.

[10] Holschuh, J.P., Nist, S.L. and Olejnik, S. (2001) Attributions to Failure: The Effects of Effort, Ability, and Learning Strategy Use on Perceptions of Future Goals and Emotional Responses. Reading Psychology, 22, 153-173. https://doi.org/10.1080/027027101753170601

[11] Fichten, C.S., Nguyen, M.N., Budd, J., Asuncion, J., Tibbs, A., Jorgensen, M. and Amsel, R. (2014) College and University Students with Disabilities: "Modifiable" Personal and School Related Factors Pertinent to Grades and Graduation. Journal of 
Postsecondary Education and Disability, 27, 273-290.

[12] Roberts, K.D., Park, H.J., Brown, S. and Cook, B. (2011) Universal Design for Instruction in Postsecondary Education: A Systematic Review of Empirically Based Articles. Journal of Postsecondary Education and Disability, 24, 5-15.

[13] Center for Universal Design (1997) The Principles of Universal Design. https://www.ncsu.edu/ncsu/design/cud/about_ud/udprinciples.htm

[14] National Center on Universal Design for Learning (2013) Universal Design for Learning. http://www.udlcenter.org/aboutudl/udlguidelines/udlguidelines_graphicorganizer

[15] Burgstahler, S. (2001) Universal Design of Instruction. University of Washington, Seattle. http://files.eric.ed.gov/fulltext/ED468709.pdf

[16] Dell, C.A., Dell, T.F. and Blackwell, T.L. (2015) Applying Universal Design for Learning in Online Courses: Pedagogical and Practical Considerations. The Journal of Educators Online, 12, 166-192. https://doi.org/10.9743/JEO.2015.2.1

[17] Scott, S.S., McGuire, J.M. and Shaw, S.F. (2003) Universal Design for Instruction: A New Paradigm for Adult Instruction in Postsecondary Education. Remedial and Special Education, 24, 369-379. https://doi.org/10.1177/07419325030240060801

[18] (2004) Individuals with Disabilities Education Improvement Act of 2004, Pub. L. No. 108-446, 118 Stat. 2647.

[19] Cornelius, K.E. and Nagro, S.A. (2014) Evaluating the Evidence Base of Performance Feedback in Preservice Special Education Teacher Training. Teacher Education and Special Education, 37, 133-146. https://doi.org/10.1177/0888406414521837

[20] Basham, J.D., Lowrey, A.K. and deNoyelles, A. (2010) Computer-Mediated Communication in the Universal Design for Learning Framework for Preparation of Special Education Teachers. A Journal of Special Education Technology, 25, 31-44. https://doi.org/10.1177/016264341002500203

[21] Izzo, M.V., Murray, A. and Novak, J. (2008) The Faculty Perspective on Universal Design for Learning. Journal of Postsecondary Education and Disability, 21, 60-72.

[22] Kumar, K.L. and Wideman, M. (2014) Accessible by Design: Applying UDL Principles in a First Year Undergraduate Course. Canadian Journal of Higher Education, 44, 125-147.

[23] McGhie-Richmond, D. and Sung, A.N. (2013) Applying Universal Design for Learning to Instructional Lesson Planning. International Journal of Whole Schooling, 9, 43-59.

[24] Parker, D.R., Robinson, L.E. and Hannafin, R.D. (2007) “Blending” Technology and Effective Pedagogy in a Core Course for Preservice Teachers. Journal of Computing in Teacher Education, 24, 49-54.

[25] Wynants, S.A. and Dennis, J.M. (2017) Embracing Diversity and Accessibility: A Mixed Methods Study of the Impact of an Online Disability Awareness Program. Journal of Postsecondary Education and Disability, 30, 33-48.

[26] Dallas, B.K., Long, G. and McCarthy, A.K. (2016) Assessing the Effects of Closed-Captioning on Undergraduate Students' Recall and Understanding of Video-Based Information. Journal on Excellence in College Teaching, 27, 117-129.

[27] Dean, T., Lee-Post, A. and Hapke, H. (2017) Universal Design for Learning in Teaching Large Lecture Classes. Journal of Marketing Education, 39, 5-16. https://doi.org/10.1177/0273475316662104

[28] Lombardi, A., Vukovic, B. and Sala-Bars, I. (2015) International Comparisons of Inclusive Instruction among College Faculty in Spain, Canada, and the United 
States. Journal of Postsecondary Education and Disability, 28, 447-460.

[29] Schelly, C.L., Davies, P.L. and Spooner, C.L. (2011) Student Perceptions of Faculty Implementation of Universal Design for Learning. Journal of Postsecondary Education and Disability, 24, 17-30.

[30] Smith, F.G. (2012) Analyzing a College Course That Adheres to the Universal Design for Learning (UDL) Framework. Journal of the Scholarship of Teaching and Learning, 12, 31-61.

[31] Spooner, F., Baker, J.N., Harris, A.A., Ahlgrim-Delzell, L. and Browder, D.M. (2007) Effects of Training in Universal Design for Learning on Lesson Plan Development. Remedial and Special Education, 28, 108-116. https://doi.org/10.1177/07419325070280020101

[32] Street, C.D., Koff, R., Fields, H., Kuehne, L., Handlin, L., Getty, M. and Parker, D.R. (2012) Expanding Access to STEM for At-Risk Learners: A New Application of Universal Design for Instruction. Journal of Postsecondary Education and Disability, 25, 363-375.

[33] Black, R.D., Weinberg, L.A. and Brodwin, M.G. (2015) Universal Design for Learning and Instruction: Perspectives of Students with Disabilities in Higher Education. Exceptionality Education International, 25, 1-26.

[34] Embry, P.B., Parker, D.R., McGuire, J.M. and Scott, S.S. (2005) Postsecondary Disability Service Providers' Perceptions about Implementing Universal Design for Instruction (UDI). Journal of Postsecondary Education and Disability, 18, 34-48.

[35] McGuire-Schwartz, M.E. and Arndt, J.S. (2007) Transforming Universal Design for Learning in Early Childhood Teacher Education from College Classroom to Early Childhood Classroom. Journal of Early Childhood Teacher Education, 28, 127-139. https://doi.org/10.1080/10901020701366707

[36] Zhang, Y. (2005) Collaborative Professional Development Model: Focusing on Universal Design for Technology Utilization. ERS Spectrum, 23, 31-38.

[37] Rose, D., Harbour, W., Johnston, C., Daley, S. and Abarbanell, L. (2006) Universal Design for Learning in Postsecondary Education: Reflections on Principles and Their Application. Journal of Postsecondary Education and Disability, 19, 135-151.

[38] Davies, P.L., Schelly, C.L. and Spooner, C.L. (2013) Measuring the Effectiveness of Universal Design for Learning Intervention in Postsecondary Education. Journal of Postsecondary Education and Disability, 26, 95-220.

[39] Burgstahler, S.E. (2008) Universal Design in Higher Education. In: Burgstahler, S.E. and Cory, R.C., Eds., Universal Design in Higher Education: From Principles to Practice, Harvard Education Press, Cambridge, 3-20.

[40] Lombardi, A., Gerdes, H. and Murray, C. (2011) Validating an Assessment of Individual Actions, Postsecondary, and Social Supports of College Students with Disabilities. Journal of Student Affairs Research and Practice, 48, 107-126. https://doi.org/10.2202/1949-6605.6214

[41] Hall, T.E., Cohen, N., Vue, G. and Ganley, P. (2015) Addressing Learning Disabilities with UDL and Technology: Strategic Reader. Learning Disability Quarterly, 38, 72-83. https://doi.org/10.1177/0731948714544375

[42] McGlaughlin, S.M., Knoop, A.J. and Holliday, G.A. (2005) Differentiating Students with Mathematics Difficulty in College: Mathematics Disabilities vs. No Diagnosis. Learning Disability Quarterly, 28, 223-232. https://doi.org/10.2307/1593660

[43] Lerman, D.C., Hawkins, L., Hillman, C., Shireman, M. and Nissen, M.A. (2015) Adults with Autism Spectrum Disorder as Behavior Technicians for Young Child- 
ren with Autism: Outcomes of a Behavioral Skills Training Program. Journal of Applied Behavior Analysis, 48, 233-256. https://doi.org/10.1002/jaba.196

[44] Nuernberger, J.E., Ringdahl, J.E., Vargo, K.K., Crumpecker, A.C. and Gunnarsson, K.F. (2013) Using a Behavioral Skills Training Package to Teach Conversation Skills to Young Adults with Autism Spectrum Disorders. Research in Autism Spectrum Disorders, 7, 411-417. https://doi.org/10.1016/j.rasd.2012.09.004

[45] Loe, I.M. and Feldman, H.M. (2007) Academic and Educational Outcomes of Children with ADHD. Journal of Pediatric Psychology, 32, 643-654.

https://doi.org/10.1093/jpepsy/jsl054

[46] Pace, D. and Schwartz, D. (2008) Accessibility in Post-Secondary Education: Application of UDL to College Curriculum. US-China Education Review, 5, 20-26.

[47] Grande, M. and Pontrello, C. (2016) Teacher Candidates Implementing Universal Design for Learning: Enhancing Picture Books with QR Codes. Journal on School Educational Technology, 12, 11-23.

[48] Pearson, M. (2015) Modeling Universal Design for Learning Techniques to Support Multicultural Education for Pre-Service Secondary Educators. Multicultural Education, 22, 27-34.

[49] Seok, S. and DaCosta, B. (2014) Development and Standardization of an Assistive Technology Questionnaire using Factor Analyses: Eight Factors Consisting of 67 Items Related to Assistive Technology Practices. Assistive Technology, 26, 1-14. https://doi.org/10.1080/10400435.2013.778917

[50] Seok, S. (2008) Teaching Aspects of E-Learning. The International Journal on E-Learning, 7, 725-741.

[51] Seok, S. (2009) Item Validation of Online Postsecondary Courses: Rating the Proximity between Similarity and Dissimilarity among Item Pairs (Validation Study Series I: Multidimensional Scaling). Educational Technology Research and Development, 57, 665-684. https://doi.org/10.1007/s11423-007-9072-3 